\section{Diagnóstico dos Nódulos Tiveóideos Baseado na Avaliação Ultra-Sonográfica e Citológica Combinada}

A PRESENÇA DE NÓDULO TIREÓIDEO é um achado comum principalmente com a utilização de métodos de diagnóstico por imagem. Diante da descoberta de um nódulo, a principal meta tem sido a de selecionar para cirurgia aqueles que possuem risco de serem malignos e evitar cirurgia desnecessária para nódulos que possuem características benignas. É necessário pois estabelecer critérios que nos indiquem em quais pacientes há indícios de malignidade suficientes para indicar cirurgia.

O exame clínico é considerado insatisfatório na detecção do nódulo tireóideo bem como na determinação do volume da glândula (1), embora a palpação continue sendo o método de escolla na avaliação das doenças difusas e nodulares da tireóide.

A utilização da ultra-sonografia que fornece dados que reproduzem o quadro anatômico macroscópico da tircóide através da avaliaçăo do seu volume, ecogenicidade, contornos, presença ou não de calcificações, muito tem auxiliado na avaliação da tireóide (2). Por não ser invasivo, de făcil realização e altamente sensível no diagnóstico dos nódulos, o ultra-som deve ser indicado, em nossa opinião, como primeiro exame na avaliação dos nódulos tireóideos. O exame ultra-sonográfico freqüentemente altera a avaliação clínica dos nódulos e a sua utilização tem aumentado a incidência de nódulos, quer sejam únicos ou múltiplos (3-5). Brander (1), cm uma série de 77 nódulos diagnosticados pelo ultra-som, mostrou que 43 deles não foram diagnosticados pela palpação, sendo que um número considerável deles tinham diâmetro maior que $2 \mathrm{~cm}$.

A punção aspirativa por agulha fina (PAAF), que permite analisar o aspecto microscópico das lesões tireóideas, é um método de valor indiscutível no diagnóstico dessas lesões e, associado ao exame ultra-sonográfico que nos dá uma idéia da macroscopia da glândula, permite que cheguemos a um diagnóstico mais preciso da lesão.

A PAAF, quando guiada pelo ultra-som, diminui as dificuldades técnicas para obtenção de material adequado e permite a punção de nódulos pequenos ou de difícil palpação. Outra vantagem é a possibilidade da escolha da região do nódulo a ser puncionado quando se trata de nódulo misto ou com área de degeneração cística, diminuindo a porcentagem de material insuficiente ou inadequado ao diagnóstico. Além disso, permite selecionar os nódulos com características ultra-sonográficas sugestivas de malignidade em uma tireóide multinodular, possibilitando o diagnóstico de câncer, ainda que associado a um bócio colóide adenomatoso (6).

\section{Avaliação Ultra-sonográfica}

Vantagens do uso do Ultra-som:

- maior acurácia que a palpação para diagnosticar nódulos pequenos, múltiplos, nódulos não palpáveis ou não esperados;

- confirmar o diagnóstico feito pelo exame físico, pois a palpação artigo original

Rosalinda Y. A. de Camargo
Eduardo Kiyoshi Tomimori

Unidade de Tireóide, Disciplina de Endocrinologia Hospital das Clínicas da FMUSP 
pode detectar um pseudo nódulo que, ao ultra-som, pode corresponder a um lobo tircóideo normal; esse falso nódulo, se submetido à PAAF, terá diagnóstico citológico de Padrão Folicular e poderá resultar em cirurgia desnecessária;

- encaminhar para a PAAF somente os nódulos suspeitos;

- selecionar o nódulo suspeito para PAAF cm uma tireóide multinodular; a neoplasia maligna freqüentemente está associada a outros nódulos benignos;

- reduzir os custos na avaliação dos nódulos tireóideos, indicando a PAAF somente para os nódulos suspcitos.

As lesōes nodulares são classificadas de acordo com os aspectos ultra-sonográficos (contorno, ecogenicidade, presença de microcalcificações), segundo critérios adaptados de Yokozawa (7), em graus de I a IV e scores de 1 a 4 para cada grau respectivamente, sendo graus I e II prováveis nódulos benignos, III suspeito para neoplasia c IV provável nóduto maligno.

\section{Classificação ultra-sonográfica dos nódulos tireóideos:}

Grau I (score I): pequena imagem anecóica arredondada, compatível com cisto de tireóide.

Grau II (score 2): nódulos de textura mista e imagens nodulares sólidas isoecóicas ou hiperecóicas acompanhadas ou não de calcificações grosseiras, componente líquido e com o restante do parênquima de textura heterogênea, são compatíveis com Bócio Colóide Adenomatoso; nódulo isoecóico, de textura homogênea, com halo hipoecóico periférico em tireóide de volume e ecogenicidade normais é sugestivo de Adenoma Folicular.

Grau III (score 3): nódulo sólido hipoccóico, de contorno regular e nódulo cístico com componente sólido em seu interior são considerados duvidosos e podem corresponder a neoplasia.

Grau IV (score 4): nódulo sólido hipoecóico, de contorno impreciso e com microcalcificações; é considerado suspeito para malignidade e sugestivo de câncer da tircóide.

\section{Avaliação citológica dos nódulos tireóideos}

A punção aspirativa por agulha fina (PAAF), em nosso serviço, é realizada utilizando-se agulha $22 \mathrm{G}$ e seringas descartáveis de $10 \mathrm{cc}$, sem o dispositivo adaptador da seringa, utilizando-sc o método descrito por
Yokozawa (7). Todas as PAAFs realizadas são guiadas pelo ultra-som.

As lâminas fixadas em álcool $96^{\circ}$ são coradas pela haematoxilina-eosina. Os exames citológicos são analisados c agrupados $\mathrm{cm}$ padrōes citológicos, segundo critérios de Bisi e col. (8). Estes são classificados, de acordo com as características citológicas, em graus de I a IV e scores de 1 a 6 , sendo I provável nódulo benigno, II duvidoso, III suspeito para neoplasia c IV maligno.

\section{Classificação citológica dos nódulos}

Padrão Folicular grau I (score 1): células em arranjo folicular com núcleos redondos ou ovalados, com cromatina densa e uniformemente distribuída, citoplasma cosinófilo e sem grânulos, grande quantidade de substrato protéico colóide e presença ou não de macrófagos fagocitanto hemossiderina. $O$ diagnóstico provávcl é Bócio Colóide Adenomatoso (BCA).

Padrão Folicular grau II (score 2): grande quantidade de células em arranjo sólido ou folicular. Os núcleos são redondos ou ovalados com cromatina uniformemente distribuída. O citoplasma é levemente eosinófilo e sem grânulos e o colóide escasso ou ausente. Este padrão pode ser cncontrado nas áreas adenomatosas de BCA ou em ncoplasias foliculares diferenciadas.

Padrão Suspeito grau III (score 3): grande quantidade de células que podem estar dispostas em blocos sólidos, em arranjo folicular ou papilífero. Os núcleos apresentam anisocariose (alteração do volume nuclcar), cromatina irregularmente distribuída e nucléolos procminentes. O citoplasma é levemente cosinófilo e sem grânulos ou volumoso, eosinófilo e finamente granular, caracterizando células de Hürthle. O colóide é escasso ou ausente. Este padrão é sugestivo de neoplasia

Padrão citológico maligno grau IV (score 6):

Padrão Papilífero: grande quantidade de células em blocos sólidos on em arranjo papilífero. Os núcleos apresentam anisocariose, cromatina irregularmente distribuída, nucléolos proeminentes, presença de dobras da membrana nuclear ("crease") e inclusão citoplasmática intra-nuclear. Este padrão é encontrado no carcinoma papilífero.

Padrão Medular: grande quantidade de células isoladas ou agrupadas que podem se apresentar plasmocitóides, redondas, ovais, poligonais ou fusiformes. Os núcleos podem ser excêntricos e, entre essas células neoplásicas, podemos observar substância hialina e amorfa caracterizando o amilóide. Este padrão é encontrado no carcinoma medular. 
Padrão Anaplásico: grande quantidade de células isoladas ou agrupadas em arranjo sólido. Os núcleos podem se apresentar únicos ou múltiplos, de contornos irregulares, com acentuado grau de anisocarjose, cromatina grosseiramente distribuída, nucléolos proeminentes, bem como mitoses atípicas c aberrantes. Este padrão é encontrado no carcinoma anaplásico.

Grande quantidade de células linfóides monomórficas é encontrado no linfoma de tireóide.

Tabela 1. Classificação combinada dos nódulos tireóideos.

\begin{tabular}{cc}
\hline ÍNDICE & DIAGNÓSTICO \\
PROVÁVEL \\
classificação & \\
uitra-sonográfica & \\
e citológica & benigno \\
\hline 2 a 4 & duvidoso \\
5 & suspeito \\
6 & maligno \\
7 a 10 & \\
\hline
\end{tabular}

A avaliação final do nódulo se baseia então nas suas características macroscópicas, definida através do exame ultra-sonográfico e nas características microscópicas obtidas através do exame citológico.

Para obtermos uma classificação combinada (ultra-sonográfica + citológica) dos nódulos, damos um score para cada grau das classificações ultra-sonográfica e citológica e a soma dos scores da classificação ultra-sonográfica e citológica resultam em índices que variam de 2 a 10 . Quanto maior o índice, maior a probabilidade de malignidade (tabela 2 ). cirurgia e somente um paciente com índice 5 tinha lesão maligna (carcinoma papilifero) ao exame anatomopatológico (tabela 2).

Nesta série, o índice derivado da classificação ultra-sonográfica e citológica combinada teve especificidade de $53 \%$ e sensibilidade de $98 \%$. O valor preditivo de um diagnóstico positivo para malignidade foi de $77 \%$ e o valor preditivo negativo para malignidade foi de $94 \%$.

A acurácia do índice combinado da classificação ultra-sonográfica e citológica foi de $80,5 \%$. Portanto, o exame ultra-sonográfico pode ajudar a selecionar os nódulos que deverão ser submetidos à PAAF, evitando puncionar todos os nódulos diagnosticados pelo ultra-som.

\section{DISCUSSĀO}

Quando avaliamos os nódulos clinica c laboratorialmente, cerca de $75 \%$ deles são encaminhados para cirurgia desnecessariamente, resultando em remoção de nódulos benignos. Já, quando a indicação cirúrgica ć baseada na PAAF, ć possível reduzir o número de cirurgias para menos de $20 \%$ e mais de $50 \%$ das lesöes são malignas (9).

Quando avaliamos os aspectos macroscópicos da tireóide, através do exame ultra-sonográfico, temos a condição de selecionar os nódulos suspeitos para PAAF. Os nódulos considerados benignos ao ultrasom (grau I e II na classificação ultra-sonográfica) raramente são malignos c a PAAF não é um procedi-

Tabela 2. Correlação entre a classificação ultra-sonográfica e cifológica combinada e o exame anatomopatológico em pacientes com nódulos tireóideos $(n=77)$.

\begin{tabular}{|c|c|c|c|c|c|c|c|}
\hline Indice & $\begin{array}{l}\text { T. Hashimoto } \\
(n=1)\end{array}$ & $\begin{array}{l}\text { BCA } \\
(n=18)\end{array}$ & $\begin{array}{r}\text { Adenoma } \\
(n=11)\end{array}$ & $\begin{array}{c}\text { Ca papilifero } \\
(n=39)\end{array}$ & $\begin{array}{c}\text { Ca folicular } \\
(n=5)\end{array}$ & $\begin{array}{c}\text { Ca medular } \\
(n=3)\end{array}$ & $\begin{array}{c}\text { Total } \\
(n=77)\end{array}$ \\
\hline $\begin{array}{l}3 \text { a } 4 \\
5 \\
6 \\
7 \text { a } 10\end{array}$ & 9 & $\begin{array}{l}1 \\
8\end{array}$ & $\begin{array}{l}4 \\
1 \\
6\end{array}$ & $\begin{array}{c}1 \\
3 \\
35\end{array}$ & $\begin{array}{l}3 \\
2\end{array}$ & 3 & $\begin{array}{c}13 \\
4 \\
20 \\
22\end{array}$ \\
\hline Total & 1 & 18 & 11 & 39 & 5 & 3 & 77 \\
\hline
\end{tabular}

\section{Nossa Experiência}

Baseada na classificação ultra-sonográrica e citológica combinada, encaminhamos para cirurgia 60 pacientes que apresentaram índice maior ou igual a 6 . Destes, 46 $(76,7 \%)$ revelaram serem portadores de lesões malignas (38 carcinomas papiliferos, 5 carcinomas foliculares e 3 carcinomas medulares) e $14(23,3 \%)$ portadores de lesões benignas ( 8 bócio colóide adenomatoso e 6 adenomas). Treze pacientes portadores de nódulos classificados como benignos (índice 3 a 4 ) e 4 pacientes com nódulos duvidosos (índice 5) foram encaminhados à mento obrigatório. Segundo alguns autores (10), a probabilidade de um nódulo isoecóico ser maligno é de $1 / 1000$.

Pela análise citológica, tivemos 2 casos classificados como grau II (escore 2) que, no entanto, foram classificados como grau IV (escore 4) pelo ultra-som; portanto, ao somarmos os escores, obteve índice 6 (suspeito para malignidade) na classificação combinada e foram encaminhados à cirurgia. O exame anatomopatológico dos dois casos confirmaram malignidade (carcinoma papilífero e carcinoma folicular). 
Os nossos dados nos permitem sugerir que todos os nódulos classificados como grau igual ou maior que III ao ultra-som devem ser submetidos à PAAF c todos os nódulos quc obtiverem índice maior ou igual a 6 na classificação combinada devem ser encaminhados à cirurgia.

Acreditamos com isso, poder reduzir consideravelmente o número de cirurgias desnecessárias e aumentar a incidência de câncer no material cirúrgico.

\section{REFERÊNCIAS}

1. Brander A, Viikinkoski P, Tuuhea J, Voutilainen L, Kivisaar $L$. Clinical versus ultrasound examination of the thyroid gland in common clinical practice. J Clin Ultrasound 1992; 20:37-42.

2. Müller HW, Schröder S, Schneider C, Seifert G. Sono graphic tissue characterisation in thyroid gland diagnosis. A correlation between sonography and histology. Klin Wochenschr. 1985; 63:706-10.

3. Harlocker TT, Hay JE, James EM, Reading CC. Charboneau WJ. Prevalence of incidental nodular thyroid disease detected during high-resolution parathyroid ultrasonography. In: Medeiros-NetoGA, Gaitan E (eds) Frontiers in Thyroidology, vol. 2, Plenum Press, New York, p 1309. 1986

4. Carrol AB. Asyntomatic thyroid nodules: Incidentai sono graphic detection. Am J Roentg 1982; 138:499-501.
5. Tomimori EK, Pedrinola F, Cavaliere H, Knobel M. Medeiros-Neto GA. Prevalence of incidental thyroid disease in a relatively low iodine intake area. Thyroid 1995; 5(4):273-6

6. Yokozawa T, Fukata S, Kuma K, Matsuzuka F, Kobayashi A, Hirai $K$, et al. Thyroid cancer detected by ultrasound guided fine-needle aspiration biopsy. World J Surg 1996; 20:848-53.

7. Yokozawa T, Miyauchi A, Kuma K, Sugawara M. Accurate and simple method of diagnosing thyroid nodules by the modified technique of ultrasound-guided fine needle aspiration biopsy. Thyroid 1995; 5(2):141-5.

8. Bisi H, Camargo RYA, Longatto Filho A. Role of fine-needle aspiration cytology in the management of thyroid nodules: review of experience with 1925 cases. Diagn Cytopathol 1992; 8:504-10.

9. Gharib $H$. Management of thyroid nodules: another look. Thyroid Today 1997; 20(1):1-11.

10. Klima. L'échographie de la thyroïde. Deuxième édition. Urban \& Schwarzenberg, 1995

\section{Endereço para correspondência:}

Rosalinda Y.A. de Camargo

Caixa Postal 3671

01060-970 São Paulo, SP

Fone: 282-8522, Fax: $217-3367$

Email: tireóide@uol.com.br / uspaaf@uol.com.br 